\title{
Effect of Hyoscine Butylbromide in Shortening the Active Phase of the First Stage of Labor in Term Pregnant Women
}

\author{
Alen Kinyina ${ }^{1}$, Sarah Chamos $^{2}$, Glorialoveness S Lyimo ${ }^{3}$ \\ ${ }^{1}$ Open University of Tanzania (OUT), Dar es salaam-Tanzania \\ ${ }^{2}$ Sekou Toure Regional Referral Hospital, Mwanza-Tanzania \\ ${ }^{3}$ University of Dodoma, College of Health Science, Tanzania
}

\begin{abstract}
:-
$>$ Background:

Various studies revealed that what matters for women during labour is short duration painless labour which results to better birth outcome. Various drugs and methods used to hasten labour both traditionally and in modern obstetrics to minimize the risks of prolonged labour.
\end{abstract}

\section{Objectives:}

To assess the effects of Hyoscine Butylbromide in shortening active phase of the first stage of labour in term pregnant women.

\section{Methodology:}

This study was designed as a double-blind, randomized, controlled, clinical trial comparing two groups of 200 term pregnant women, where by the intervention group received $20 \mathrm{mg}$ of hyoscine butylbromide intravenously while the control group received $1 \mathrm{ml}$ normal saline via the same route during the active phase of labour with cervix dilatation confirmed to be 4-5 centimeters. The progress of labour for both groups was closely monitored and documented according to the principles of active management of labour. Both women and birth attendants were blinded on the contents of the syringes.

\section{$>$ Results:}

The mean rate of cervical dilatation in $\mathrm{cm}$ per hour in hyoscine group was $2.6 \pm 0.9$ and in normal saline was $1.8 \pm 0.8$ the mean difference was statistical significance $(p=<0.05)$. The duration of the active phase of the first stage of labour was shorter in hyoscine group (190.1 \pm 128.9$)$ minutes compared to $266.8 \pm 123.2$ minutes of normal saline group $(P=0.001)$. The characteristics of women including mean age, gestational age and parity were similar in both groups. The Apgar score of hyoscine group and normal saline group were similar and the differences were not statistically significant.

\section{Conclusion:}

Hyoscine butylbromide is effective drug in shortening the active stage of the first stage of labour in term pregnant women. The drug has no effect during the second and the third stage of labour and no obvious adverse effect to mothers and newborn.

Keywords:- First stage, Hyoscine butylbromide, Labour,Pregnant.

\section{INTRODUCTION}

Most pregnant women would prefer a shorter and painless labor with outcome of a healthy baby and minimal trauma to mother. ${ }^{[1,2]}$ Prolonged labour is one of the risk factor contributing to maternal and fetal exhaustion, postpartum hemorrhage(PPH) and sepsis. [3] Therefore, shortening of duration of labour contribute to the reduction of maternal and neonatal morbidity and mortality. ${ }^{[4]}$ The active phase of first stage of labor starts when cervix dilated from $4 \mathrm{~cm}$, with substantial degree of effacement and regular uterine contractions and end with complete dilatation of cervix at 10 cm. ${ }^{[1]}$

The achievements of the first stage of labor result from changes in the biochemical connective tissue and with gradual effacement and uterine cervix dilatation as a result of rhythmic uterine contractions of frequency, sufficient, intensity, and duration. ${ }^{[5]}$ When necessary obstetricians or midwives use cervical ripening agents such as prostaglandins to decrease the duration of labour. ${ }^{[5,6]}$

It was custom for labor to follow the natural processes without the application of any method to accelerate it (passive management of labor) until in the beginning of the 20th century, in 1906, when the first uterotonic called oxytocin was discovered, and when its implementation began to accelerate labor (active management) in 1911. ${ }^{[7]}$

The principle of active management of labour was introduced in Dublin to shorten the length of labour while maintaining a low rate of caesarean section delivery, the active management of labour refers to active control, rather than passive observation over the course of labour by the obstetric provider. ${ }^{[5,8]}$ There are various methods which facilitate cervical dilatation including pharmacological and mechanical such as sweeping of membrane and cervix and use of other prostaglandins for labour induction. ${ }^{[2,9]}$ Active management of labour is part and parcel of modern obstetrics care. ${ }^{[2]}$ 
Hyoscine butylbromide (also known as scopolamine) or buscopan is a quaternary ammonium derivative, which act by exerting a spasmolytic action on the smooth muscle of the genitourinary tracts, biliary and gastrointestinal tracts. ${ }^{[4,5,8,10]}$ The substance is rapidly distributed ( $\mathrm{t} 1 / 2=29$ minutes) into the tissues after intravenous administration. ${ }^{[8,10]}$ Hyoscine-Nbutylbromide does not pass the blood-brain barrier, and has low plasma protein binding; almost half of the clearance is renal, and the main metabolites are found in urine. ${ }^{[5,10]}$

This medication does not have proven adverse effects during pregnancy or lactation; however, hyoscine is recommended with caution during the first trimester. Side effects include: dry mouth, intermittent loss of accommodation reflexes, facial flushing, constipation, and urinary retention. ${ }^{[8,11]}$

This study aimed at accessing the effect of hyoscine butylbromide in shortening the first stage of labor in Term pregnant women.

\section{METHODOLOGY}

The study was designed as a double-blind, randomized, controlled, clinical trial comparing two groups of term pregnant women: one group received hyoscine butylbromide, while other group received the normal saline (placebo). The study was conducted at Kilimanjaro Christian Medical Center from December 2016 to July 2017.

The syringes containing Hyoscine and normal saline were prepared by the Registered midwife. Each syringe contained either $1 \mathrm{ml}$ of drug (20 mg) or $1 \mathrm{ml}$ of placebo; both liquids are colorless, so both drug and placebo were indistinguishable from each other. Sterile syringes were then assigned the random numbers. Only the study investigator knew the relation between the labels of the syringes and their contents. The women were administered the contents as a single dose, given intravenously, when they were assessed and confirmed as being in labour, with cervical dilatation of 4-5 $\mathrm{cm}$, as confirmed and documented by registered midwife or obstetrician. The women were blinded as to whether they received the active drug or placebo.
Birth attendant who was monitoring labour was blinded on the contents of each syringes albeit participants were informed to report any side effect to the birth attendant although were not recorded to be analyzed as variables. The progress of labour for both drug and control group was closely monitored and documented according to the principles of active management of labour and hospital protocols and guideline for labour management.

The data were analyzed by using the Statistical Package for the Social Sciences (SPSS) version 20 for Window (SPSS Inc., Chicago, IL, USA). The statistical differences between the intervention and control groups were compared with $\chi^{2}$ or Fisher's exact test in the case of categorical variables and with the Student's $t$-test for continuous variables.

Inclusion criteria were: Gestational age between completed 37- 41 weeks +6 days, uncomplicated cephalic singleton pregnancy occipito-anterior position, average size and viable baby, no evidence of maternal or fetal distress.

Exclusion criteria were: Malpresentation and malposition, indications of elective caesarean section, medical conditions associated with pregnancy e.g. preeclampsia, diabetes mellitus, history cervical surgery, multiple fetus, allergic to hyoscine, Contraindication for vaginal delivery.

Withdraw criteria: caesarean section before complete dilatation, administration of hyoscine butylbromide antagonistic drugs.

\section{RESULTS}

Total 200 women who met all eligibility criteria were recruited in this study, no women who withdrew from the study. The characteristics of women including mean age, gestational age and cervical dilatation at time of administering hyoscine or normal saline and number of parity were similar in both intervention and control groups. Augmentation of labour with oxytocin was $43 \%$ in hyoscine group and 59\% in normal saline group although difference was not statistical significant $(\mathrm{p}=>0.05)$. (Table 1$)$

\begin{tabular}{|c|c|c|c|}
\hline Variables & Hyoscine $n=100$ & Normal saline $\mathbf{n}=\mathbf{1 0 0}$ & P value \\
\hline Age $($ mean $\pm \mathrm{SD})$ & $27.6 \pm 4.6$ & $27.4 \pm 4.9$ & $>0.05$ \\
\hline Gestation age $($ mean \pm SD $)$ & $38.5 \pm 1.9$ & $38.7 \pm 1.7$ & $>0.05$ \\
\hline Prime gravida $(\%)$ & $37(37)$ & $42(42)$ & \multirow[t]{2}{*}{$>0.05$} \\
\hline Multigravida (\%) & $63(63)$ & $59(59)$ & \\
\hline $\begin{array}{l}\text { Cervical dilatation during administration of Hyoscine/ } \\
\text { Normal saline (mean } \pm \text { SD) }\end{array}$ & $5.3 \pm 0.6$ & $5.1 \pm 0.8$ & $>0.05$ \\
\hline Augmentation of labor with oxytocin (\%) & $43(43)$ & $59(59)$ & $>0.05$ \\
\hline
\end{tabular}

Table 1:- Comparison of the characteristics of Respondents in Hyoscine group and Normal saline group

The labour duration characteristics were compared by rate of cervical dilatation per hour and the duration of active phase of first stage of labour. The mean rate of cervical dilatation in $\mathrm{cm}$ per hour in hyoscine group was $2.6 \pm 0.9$ and in normal saline was $1.8 \pm 0.8$ the mean difference was statistical significance $(\mathrm{p}=<0.05)$. The duration of the active phase of the first stage of labour was shorter in hyoscine group (190.1 \pm 128.9$)$ minutes compared to $266.8 \pm 123.2$ minutes of normal saline group. The mean difference between these two groups was highly statistical significance $(p=<0.001)$. The duration of the second and third stage of labour were similar in both hyoscine and normal saline group. (Table 2). 
ISSN No:-2456-2165

\begin{tabular}{|l|l|l|l|}
\hline Variables & Hyoscine n=100 & Normal saline n=100 & P value \\
\hline Mean rate of cervical dilatation in cm /hour(mean \pm SD) & $2.6 \pm 0.9$ & $1.8 \pm 0.8$ & $<0.05$ \\
\hline Duration of active phase of first stage of labor in minutes(mean \pm SD) & $190.1 \pm 128.9$ & $266.8 \pm 123.2$ & $<0.001$ \\
\hline Duration of second stage of labor in minutes(mean \pm SD) & $20 \pm 5.2$ & $20.2 \pm 9.8$ & 0.6 \\
\hline Duration of third stage of labor in minutes(mean \pm SD) & $5.1 \pm 1.4$ & $5.9 \pm 1.1$ & 0.5 \\
\hline Mode of delivery & & & \\
\hline Spontaneous Vaginal delivery (SVD) & $94(94 \%)$ & $89(89 \%)$ & 0.2 \\
\hline Caesarean section (CS) & $4(4 \%)$ & $9(9 \%)$ & 0.09 \\
\hline Vacuum Assisted delivery & $2(2 \%)$ & $2(2 \%)$ & 0.1 \\
\hline
\end{tabular}

Table 2:- Comparison of Labour characteristics in Hyoscine group and Normal saline group.

\begin{tabular}{|l|l|l|l|}
\hline Variables & Hyoscine $\mathbf{n = 1 0 0}$ & Normal saline $\mathbf{n = 1 0 0}$ & P value \\
\hline Apgar score at one minute $($ mean \pm SD) & $8.2 \pm 0.8$ & $8.3 \pm 0.7$ & 0.09 \\
\hline Apgar score at five minutes (mean \pm SD) & $8.8 \pm 1.2$ & $8.9 \pm 1.1$ & 0.07 \\
\hline Live birth & 100 & 100 & 0.59 \\
\hline
\end{tabular}

Table 3:- Comparison of Neonatal outcomes in Hyoscine group and Normal saline group.

The Apgar score of hyoscine group and normal saline group were similar and the differences were not statistically significant. There was no noted adverse effect noted to newborn and all babies were born alive with Apgar score of $>7$ in 1 minutes and 8-10 in 5 minutes for all neonates who were born by Caesarean section, Spontaneous Vaginal delivery and assisted vacuum delivery.

\section{DISCUSSION}

The results in this study indicates that Hyoscine butylbromide is significant effective in shortening the active phase of the first stage of labour, also based on these results and other supportive data from similar clinical trials, it is obvious that the drug is not associated with any notable adverse outcomes in mother or newborn.

However, our study found that there was no statistical difference in the duration of the second and third stages of labour indicating that the action of hyoscine butylbromide is primary on the cervix, and not so much on facilitating the uterine activity.

The similar findings reported in other several studies with the same design where by women who were administered hyoscine had shorter duration in first stage of labor compared to those in control arm. ${ }^{[4,12,13]}$ Another study that was conducted at Shahid Sadoughi Hospital -Yazd -Iran to find out effect of hyoscine butylbromide on the first stage of labour in multiparous women concluded that the drug is effective in shortening the duration of both first and second stages of labour and is not associated with any obvious adverse effect to mother or newborn. ${ }^{[4]}$

However, some studies were contrary to our study findings where by two randomized clinical trial studies conducted to assess the impact of Buscopan on the duration of first stage of labour and reported that there is no significance difference between those who were administered buscopan versus the control group. ${ }^{[14,15]}$
Our study demonstrated that the characteristics of women including mean age, gestational age and cervical dilatation at time of administering hyoscine or normal saline and number of parity have no statistically significant difference. Also the result of the present study shows that there is no obvious impact on the Apgar score of the newborn and model of delivery in both intervention and control group. The similar findings reported in other several studies where those women characteristics were not statistically significant. ${ }^{[2,4,11]}$ However one study reported the increased admission to Neonatal intensive care unit (NICU) and a higher rate of cesarean deliveries in the hyoscine group. ${ }^{[15]}$

\section{CONCLUSION}

Generally, in current modern obstetric care of active management of labour we conclude that hyoscine butylbromide is effective drug in shortening the active phase of the first stage of labor. The drug has no obvious effect on the second and third stage of labor. No noted adverse effect to mothers and newborn.

\section{RECOMENDATION}

Basing on the evidences of the present and previous studies we recommend the use of hyoscine butylbromide during the active phase of the first stage of labor especially in cases requiring intervention to ease dilation such as persistent cervical rigidity.

Further studies with large sample size should be done to find more the effect of hyoscine butylbromide in shortening the first stage of labour and associated side effects.

\section{LIMITATIONS}

This study involved both multiparous and nulliparous women, the high proportion of multigravida women in the intervention group could have effect to the shorter duration of the first stage of labour. 
The total duration of labour influenced by other factors which acts synergistically and simultaneously to facilitate good progress of labour.

\section{CONFLICT OF INTEREST: Not declared}

Investigators have no any relation or benefits in any pharmaceutical industries or commercial drugs companies.

\section{AKNOWLEDGMENT}

All maternity and OG1 staff at Kilimanjaro Christian Medical Center (KCMC).

\section{REFERENCES}

[1]. WHO (2018). Recommendations Intrapartum care for a positive childbirth experience

Available

at

https://apps.who.int/iris/bitstream/handle/10665/260178 19789241550215-eng.pdf?sequence $=1$

[2]. Kaur Sarbhjit et al., Effect of Dihydrochloride with combination of Valethamate Bromide and Hyoscine Butyl-N-Bromide on cervical dilatation. Journal of Clinical and Diagnostic Research. 2013 Sept, Vol-7(9): 1897-1899

[3]. Mohamed Ellaithy (2017) Use of Hyoscine Butyl Bromide for management of prolonged labor in nulliparous women, A randomized controlled trial. National Library of Medicine. NCT01854073 Available

at:

https://clinicaltrials.gov/ct2/show/NCT01854073

[4]. Sekhavat L, Karbasi SA, Fallah R et al. (2012): Effect of hyoscine butylbromide first stage of labour in multiparus women. Afr. Health Sci.,12(4): pp. 408-411.

[5]. Ahmad Muhammad, Gebril M. M., Farhan A. M et al Role of Intravenous Hyoscine Butylbromide injection on the duration and progress of first stage of labour in primigavidae. The Egyptian Journal of Hospital Medicine (October 2017) Vol.69 (3), Page 2052-2058.

[6]. Norwitz ER, Robinson JN and Repke JT (2004): Labor and delivery in: Normal and Problem Pregnancies 15. p215-218

[7]. Cunningham FG, McDonald MD. Williams obstetrics. 20a Edition. McGraw Hill. p. 243---292.

[8]. Samuels LA, Christie L, Roberts- Gittens B et al. (2007): The effect of hyoscine butylbromide on the first stage of labour in term pregnancies. Medscape Drugs and Diseases, 88: 319-320

[9]. Caughey AB, Sundaram V, Kaimal AJ, et al. Maternal and neonatal outcomes of elective induction of labor. Evid Rep Technol Assess. 2009; 176:1-257.

[10]. Drug Information: Buscopan_. Ingelheim, Germany: Boehringer Ingelheim Limited. Revised December 2005.

[11]. E.M. Trevĩno-Salinas, G.E. Castillo-Martín del Campo (2014) Effect of hyoscine butylbromide on cervical dilation during labor. Elsevier.
[12]. Makvandi S, Tadayon M, Abbaspour M (2011) Effect of hyoscine-N-butylbromide rectal suppository on labor progress in primigravid women:Randomized doubleblind placebo-controlled clinical trial. Croat Med J 52: 159-163.

[13]. Akleh HE, Al-Jufairi ZA (2010) Effect of Hyoscine-Nbutyl bromide (Buscopan) in accelerating first stage of labor. J Bahrain Med Soc 22:103-107.

[14]. Tarrats L, Navarri I, Paez I, Cabrera S (2019) Hyoscine Butylbromide for Cervical Rigidity in the First Stage of Labor: Randomized Clinical Trial. Gynecol Obstet (Sunnyvale) 9: 500. doi:10.4172/2161-0932.1000500

[15]. Aldahhan F, Alwaeely F, Raheen F (2011) The evaluation of the effect of Buscopan on the duration of labour. Bas J Surg 17: 25-29. 